\title{
PENGARUH METODE LATIHAN DAN KOORDINASI TERHADAP POWER TUNGKAI ATLET BOLA VOLI JUNIOR PUTRI
}

\section{THE EFFECT OF TRAINING MODELS AND COORDINATION ON THE LEG POWER OF JUNIOR FEMALE VOLLEYBALL ATHLETES}

\author{
Anung Probo Ismoko, Pamuji Sukoco \\ UT UPBJJ Yogyakarta, FIK Universitas Negeri Yogyakarta \\ anung_ismoko@ymail.com, pamuji_sukoco@uny.ac.id
}

\begin{abstract}
Abstrak
Penelitian bertujuan mengetahui: (1) Peningkatan power melalui metode latihan agility hurdle drills dan agility ring drills, (2) Perbedaan pengaruh metode latihan terhadap power tungkai, (3) Perbedaan pengaruh power tungkai antara yang memiliki koordinasi tinggi dan rendah, dan (4) Pengaruh interaksi antara metode latihan dan koordinasi terhadap power tungkai. Penelitian ini merupakan eksperimen. Populasi penelitian adalah atlet klub Bola Voli Spirit dan Pervas berjumlah 44 atlet. Sampel penelitian 24 atlet ditentukan dengan teknik sampling. Pengumpulan data menggunakan tes yang dilakukan sebelum dan sesudah perlakuan. Instrumen penelitian adalah Sargen Jump Test dan Hexagonal Obstacle Test. Teknik analisis data menggunakan ANAVA. Hasil penelitian adalah: (1) Tidak terdapat perbedaan peningkatan power tungkai yang signifikan melalui metode latihan agility hurdle drills dan agility ring drills. (2) Tidak terdapat perbedaan pengaruh antara metode latihan terhadap power tungkai. (3) Terdapat perbedaan peningkatan power tungkai antara yang memiliki koordinasi tinggi dan koordinasi rendah. (4) Tidak terdapat interaksi antara metode latihan dan koordinasi terhadap peningkatan power tungkai.
\end{abstract}

Kata kunci: agility hurdle drills, agility ring drills, power tungkai, koordinasi, bola voli.

\section{Abstract}

This study aimed to determine: (1) increase leg power through of agility hurdle drills and agility ring drills training models, (2) the differences in the effect of training models on the leg power, (3) differences in the effect of leg power between those having a high and low coordination, and (4) the effect interaction between training methods and coordination on the leg power.This study is an experimental study. The population in this study was the athletes of Volleyball Club Spirit and Pervas, totaling 44 athletes. A sample of 24 athletes was establised using the purposive sampling. The data were collected using tests and the measurements performed before and after treatment. The instruments used in this study was the Sargen Jump Test and Hexagonal Obstacle Test. The data were analyzed using the ANOVA. The results are: (1) There is no difference in effect between training methods of hurdle agility drills and agility ring drills on improved the leg power, (2) There is no difference in effect between training methods on the leg power, (3) There are differences in the leg power improvement between those having high and low coordination. (4) There is no interaction between training methods and coordination on the improvement of leg power.

Keywords: agility hurdle drills, agility drills ring, leg power, coordination, volleyball. 


\section{Pendahuluan}

Bola voli merupakan salah satu cabang olahraga yang memasyarakat di Indonesia. Pada klub bola voli era modern seharusnya sudah memulai pembinaan olahraga bola voli yang sudah dilakukan secara bertahap mulai dari tahap pemula (multilateral) sampai tahap senior sebagai persiapan pembinaan ke arah olahraga prestasi. Pembinaan-pembinaan olahraga seharusnya dilakukan secara bertahap mulai dari tahap multilateral sampai ke tahap spesialisasi. Hal ini dilakukan untuk menciptakan atlet yang dapat mencapai prestasi maksimal. Untuk pencapaian prestasi tinggi dalam olahraga, seseorang harus berlatih melalui suatu proses latihan yang terprogram dan tersusun secara sistematis yang dilakukan secara berulang-ulang dan makin hari makin bertambah beban latihannya sesuai dengan prinsip latihan.

Bompa (1999, p.54) menjelaskan bahwa ada empat tahapan yang harus diperhatikan dalam latihan yaitu, "physical training, technical training, tactical training, psychological and mental training." Empat persiapan latihan physical training, technical training, tactical training, psychological and mental training, saling berhubungan satu dengan yang lainnya. Physical training merupakan dasar bagi persiapan yang lain karena kondisi fisik merupakan kondisi organ tubuh untuk menerima dan menjalankan aktivitas yang dituntut. Persiapan fisik harus dianggap sebagai salah satu aspek yang harus diperhatikan dan dipertimbangkan dalam latihan untuk mencapai prestasi maksimal. Tujuan utama adalah untuk meningkatkan potensi fungsi alat-alat tubuh para atlet dan untuk mengembangkan kemampuan biomotor menuju tingkatan yang tertinggi. Pada atlet memasuki tingkatan umur junior adalah fase yang sangat penting untuk mengembangkan unsur biomotor. Masa atlet junior adalah masa rata-rata di mana atlet untuk memulai pengembangan dan pembentukan ke arah olahraga prestasi. Latihan-latihan biomotor sangat penting dilatihkan untuk menunjang pertumbuhan, perkembangan, kebugaran dan keterampilan-keterampilan pada olahraga bola voli. Biomotor adalah keseluruhan dari kondisi fisik olahragawan. Menurut Sukadiyanto (2010, p.82) komponen dasar biomotor adalah ketahanan, kekuatan, kecepatan dan kelentukan. Komponen lain seperti power, kelincahan, keseimbangan dan koordinasi merupakan kombinasi dan perpaduan dari beberapa komponen dasar biomotor.
Kondisi fisik merupakan unsur yang penting serta menjadi dasar atau pondasi dalam pengembangan teknik, taktik, strategi, dan mental. Status kondisi fisik dapat mencapai titik optimal apabila dimulai latihan sejak usia pemula, junior maupun sampai senior dan dilakukan secara terus-menerus sepanjang tahun dengan berpedoman kepada prinsip-prinsip dasar latihan. Latihan kondisi fisik harus dikembangkan secara menyeluruh (multilateral) sehingga mengalami perkembangan dalam berbagai unsur kemampuan fisik seperti kelentukan, kecepatan gerak (dalam bentuk speed, agility dan quickness), kekuatan (dalam bentuk power dan power endurance), serta daya tahan umum (dalam bentuk speed endurance).

Komponen biomotor power tungkai dan koordinasi merupakan prasyarat yang sangat dibutuhkan pada cabang olahraga bola voli. Dengan bertambahnya usia atlet komponen biomotor power tungkai dan koordinasi harus dilatihkan secara progresif dan kontinyu dikarenakan dengan bertambahnya usia maka unsur komponen biomotor ini akan menurun. Dalam cabang olahraga bola voli komponen biomotor power tungkai sangat dibutuhkan untuk melakukan loncatan, baik untuk melakukan serangan (smash), pertahanan (block), maupun service. Atlet yang tidak mempunyai power tungkai yang bagus tidak akan mudah untuk dapat melakukan gerakan yang bersifat eksplosif dalam waktu yang cepat.

Komponen biomotor power tungkai dan koordinasi sangat diperlukan dalam cabang olahraga bola voli. Kemampuan daya ledak otot atau sering disebut power adalah salah satu unsur fisik yang memiliki peranan penting dalam kegiatan olahraga, baik sebagai unsur pendukung dalam suatu gerak tertentu maupun unsur utama dalam pencapaian teknik gerak. Power adalah kekuatan untuk mempergunakan kekuatan maksimal yang digunakan dalam waktu yang sesingkat-singkatnya. Power merupakan salah satu komponen fisik yang harus dimiliki oleh para atlet di mana atlet harus bisa mengerahkan kekuatan secara eksplosif dalam waktu yang sesingkat-singkatnya.

Menurut Sukadiyanto (2010, p.200) urutan latihan untuk meningkatkan power diberikan setelah olahragawan dilatih unsur kekuatan dan kecepatan. Power sangat dipengaruhi oleh dua unsur komponen fisik lainnya yaitu kekuatan otot dan kecepatan. Kedua komponen fisik ini tidak dapat dipisahkan, karena pada prinsip kerjanya kedua komponen fisik ini be- 
kerja bersama-sama untuk menghasilkan kemampuan daya ledak otot (power). Dasar dari pembentukan power adalah kecepatan dan kekuatan, maka sebelum melatih kondisi fisik power maka kondisi fisik kekuatan dan kecepatan harus dilatihkan terlebih dahulu. Sebelum latihan kondisi fisik power seorang atlet harus memiliki tingkatan kekuatan dan kecepatan yang baik.

Dalam olahraga bola voli power tungkai sangat diperlukan para atlet untuk dapat melompat dan meloncat baik dalam melakukan penyerangan maupun bertahan. Dengan memiliki power tungkai yang baik diharapkan dapat meningkatkan performa dan kualitas sehingga dapat mengukir prestasi-prestasi dalam olahraga bola voli.

Koordinasi merupakan kemampuan menggabungkan sistem saraf gerak yang terpisah dengan merubahnya menjadi suatu pola gerak yang efisien. Dengan kata lain semakin komplek suatu gerakan, maka makin tinggi tingkat koordinasinya. Dengan memiliki komponen biomotor koordinasi yang baik, maka akan dapat melaksanakan gerakan secara efektif dan efisien. Efektif dalam kaitan ini berhubungan dengan efisiensi penggunaan waktu, ruangan dan energi, dalam melaksanakan suatu gerakan. Sedangkan efektif berkaitan dengan efektivitas proses yang dilalui dalam mencapai tujuan. Seorang atlet yang memiliki koordinasi yang baik maka akan mudah di dalam menguasai teknik, taktik dan meningkatkan mentalnya.

Agility hurdle drills dan agility ring drills merupakan bentuk metode latihan untuk mengembangkan komponen biomotor dengan sasaran utama power tungkai dan koordinasi yang sangat berperan dalam cabang olahraga bola voli. Dengan memiliki power tungkai dan koordinasi yang baik pada atlet junior diharapkan dapat meningkatkan pencapaian prestasi olahraga pada usia emas (golden age). Pemberian aktivitas fisik yang baik dan terprogram akan membantu atlet junior agar dapat tumbuh dan berkembang dengan baik. Pemberian program latihan yang bervariasi dan dengan metode yang kreatif akan memberikan tantangan latihan dan pada umur junior. Dengan persiapan pemrograman latihan yang baik pada atlet junior akan berpengaruh positif terhadap prestasi pada golden age dan relatif bertahan lebih lama dalam mempertahankan puncak prestasinya.

Latihan kondisi fisik untuk melatih power tungkai dan koordinasi perlu dikembangkan agar dapat meningkatkan prestasi pada cabang olahraga bola voli. Latihan yang digunakan dalam penelitian ini adalah metode latihan agility hurdle drills dan agility ring drills. Penelitian ini akan membuktikan apakah metode latihan agility hurdle drills dan agility ring drills dapat meningkatkan power tungkai dan koordinasi pada atlet putri junior bola voli. Metode latihan agility hurdle drills dan agility ring drills dipilih karena merupakan salah satu bentuk latihan yang mampu memberikan keuntungan sekaligus meningkatkan kemampuan kondisi fisik anak terutama power tungkai dan koordinasi.

Training is a planned process to modify attitude, knowledge or skill behaviour through learning experience to achieve effective performance in an activity or range of activities (Ghosh, 2005, p.7). Pada prinsipnya latihan merupakan suatu proses perubahan ke arah yang lebih baik, yaitu untuk meningkatkan: kualitas fisik, kemampuan fungsional peralatan tubuh, dan kualitas psikis anak latih (Sukadiyanto, 2010, p.1). Latihan olahraga adalah aktivitas yang dilakukan dalam suatu waktu dan dilakukan secara berulang-ulang, terprogram dalam prinsip-prinsip pembebanan latihan guna menciptakan olahragawan yang mencapai standar penampilan tertinggi. Program latihan harus mengikuti konsep periodisasi, disusun dan direncanakan secara baik berdasarkan cabang olahraga agar sistem energi atlet mampu beradaptasi terhadap kekhususan cabang olahraga. Dalam pencapaian tingkat kemampuan yang baik dalam berolahraga, proses latihan memerlukan pentahapan yang terencana secara progresif memiliki tujuan dan sasaran dengan menggunakan metode yang telah dipersiapkan secara teori dan praktek agar tercapai secara tepat, cepat, efektif, dan efisien. Sasaran dan tujuan latihan secara garis besar adalah latihan fisik, latihan teknik, latihan taktik, dan latihan mental.

Kondisi fisik merupakan satu kesatuan yang utuh dari komponen-komponen yang tidak dapat dipisahkan begitu saja, baik peningkatan maupun pemeliharaannya. Program latihan kondisi fisik harus ditata, dirancang dan dilakukan dengan baik agar mampu meningkatkan kondisi kebugaran dan kemampuan biomotorik yang dibutuhkan.

Aspek kondisi fisik merupakan bagian terpenting dalam semua cabang olahraga, terutama untuk mendukung aspek-aspek lainnya seperti teknik, taktik dan mental. Kondisi fisik sangat menentukan dalam mendukung tugas 
atlet dalam latihan maupun pertandingan sehingga diharapkan dengan mempunyai kondisi fisik yang bagus perfoma dapat ditampilkan secara maksimal. Menurut Sukadiyanto (2010, pp.9-10) sasaran utama dari latihan fisik adalah untuk meningkatkan kualitas kebugaran jasmani (energy fitness) dan kebugaran otot (muscular fitness). Fisik merupakan pondasi dari prestasi olahragawan, sebab teknik, taktik, dan mental akan dikembangkan dengan baik jika memiliki kualitas fisik yang baik. Kondisi fisik sangat menunjang dalam mempersiapkan latihan dan pertandingan, sehingga atlet tidak mengalami kelelahan yang berarti dan akan terhindar dari cedera yang akan mengganggu penampilannya. Oleh karena itu kondisi fisik sangatlah diperlukan dalam cabang olahraga bola voli.

Atlet yang mempunyai kondisi fisik yang prima, maka akan ada peningkatan dalam kemampuan sistem sirkulasi dan kerja jantung, peningkatan dalam kekuatan, kelentukan, stamina, kecepatan, kelincahan, power, koordinasi dan komponen-komponen lain kondisi fisik, ekonomi gerak yang lebih dalam latihan, recovery yang cepat dalam organ-organ tubuh, yang berperan dalam semua cabang olahraga. Unsurunsur kondisi fisik dalam olahraga yaitu: (1) kekuatan, (2) daya tahan, (3) daya ledak, (4) kecepatan, (5) kelenturan, (6) kelincahan, (7) koordinasi, (8) keseimbangan, (9) ketepatan, dan (10) reaksi. Kemampuan daya ledak otot atau sering disebut power adalah salah satu unsur fisik yang memiliki peranan penting dalam kegiatan olahraga, baik sebagai unsur pendukung dalam suatu gerak tertentu maupun unsur utama dalam pencapaian teknik gerak.

Menurut Sukadiyanto (2010, p.200) urutan latihan untuk meningkatkan power diberikan setelah olahragawan dilatih unsur kekuatan dan kecepatan. Power sangat dipengaruhi oleh dua unsur komponen fisik lainnya yaitu kekuatan otot dan kecepatan. Kedua komponen fisik ini tidak dapat dipisahkan, karena pada prinsip kerjanya kedua komponen fisik ini bekerja bersama-sama untuk menghasilkan kemampuan daya ledak otot (power). Menurut Simmons (www.westsidebarbell.com) explosive strength can be developed by using moderate resistance with maximum speed. Power is the rate at which work is performed or the rate of the transformation of metabolic potential energy to work and/or heat (Komi, 2003, p.3). Dalam olahraga bola voli power tungkai sangat diperlukan para atlet untuk dapat melompat dan meloncat baik dalam melakukan penyerangan maupun bertahan. Dengan memiliki power tungkai yang baik diharapkan dapat meningkatkan performa dan kualitas sehingga dapat mengukir prestasi-prestasi dalam olahraga bola voli.

Komponen biomotor koordinasi diperlukan pada cabang olahraga bola voli yang memerlukan gerak selaras, serasi dan simultan, sehingga gerak yang dilakukan menjadi efektif efisien dan mudah. Koordinasi adalah kemampuan menggabungkan sistem saraf gerak yang terpisah dengan merubahnya menjadi suatu pola gerak yang efisien. Makin komplek suatu gerakan, maka makin tinggi tingkat koordinasinya. Bompa (1999, p.380), menyatakan bahwa koordinasi adalah suatu kemampuan biomotorik yang sangat komplek, saling berhubungan dengan kecepatan, kekuatan, daya tahan, dan kelentukan. Fungsi koordinasi dalam bola voli adalah dapat melaksanakan gerakan secara efektif dan efisien. Efektif dalam kaitan ini berhubungan dengan efisiensi penggunaan waktu, ruangan dan energi, dalam melaksanakan suatu gerakan. Sedangkan efektif berkaitan dengan efektivitas proses yang dilalui dalam mencapai tujuan, mengkoordinasikan beberapa gerak agar menjadi satu gerak yang utuh dan serasi, efisien dan efektif dalam penggunaan tenaga, untuk menghindari cedera, mempercepat berlatih, menguasai teknik, dapat untuk memperkaya taktik dalam bertanding, kesiapan mental atlet lebih mantap untuk menghadapi pertandingan.

Metode latihan agility hurdle drill merupakan salah satu bentuk latihan power dan koordinasi yang variatif dan inovatif yang dimodifikasi menggunakan alat-alat sederhana. Hurdles are an innovative teaching tool for the enhancement of an athlete's speed, agility, quickness, and power. Hurdles can be used in a variety of exercises designed to develop quick feet, powerful explosion, and proper running technique (http://www.alphadog-sports.com/pdf/Hurdles\%20Manual.pdf). Agility hurdle drill adalah bentuk metode latihan yang digunakan untuk meningkatkan power tungkai yang berfungsi untuk meningkatkan stamina, koordinasi, kelincahan dan kecepatan. Latihan agility hurdle drill digunakan untuk menyempurnakan power, kecepatan, kelincahan, koordinasi kaki dan memperbaiki teknik olahraga. Rintangan hurdles dapat disesuaikan dan divariasikan menurut kebutuhan para atletnya. Dalam pencegahan cedera yang terjadi yaitu dengan 
menggunakan perlengkapan latihan yang memiliki standar keamanan cedera.

Metode latihan agility hurdle drill dapat dilakukan di lapangan dalam ruangan maupun luar ruangan. Metode latihan ini dirancang untuk bagaimana atlet dapat bergerak secara cepat dan mengubah arah serta melewati rintangan yang divariasikan menyerupai pada cabang-cabang olahraga yang ada. Rintangan dibuat untuk pengembangan variasi latihan menghindar, mengubah arah tubuh, power tungkai dan koordinasi gerakan-gerakan yang diperlukan dalam berbagai cabang olahraga.

Bentuk-bentuk latihan agility hurdle drill antara lain: Linear movement drills: single leg hurdle, two step high knee, one step run, long two step, alternates, staggered hurdle run. Lateral movement drills: two step laterals, lengthened four step.

Kelebihan metode latihan agility hurdle drill diantaranya adalah; (1) metode latihan agility hurdle drill menggunakan rintanganrintangan yang divariasikan dan menjadi metode latihan baru bagi atlet, sehingga atlet dalam melakukan latihan akan penasaran dan tertantang di dalam menyelesaikan sesi latihannya; (2) pelatih dapat memvariasikan dan menggabungkan berbagai macam gerakan-gerakan, sehingga selain melatih komponen biomotor power tungkai juga melatih komponen biomotor koordinasi; (3) pemrograman metode latihan agility hurdle drill yang baik akan menjadikan tingkat performa atlet menjadi optimal.

Kelemahan metode latihan agility hurdle drill diantaranya adalah; (1) metode latihan agility hurdle drill adalah metode untuk melatih power tungkai dan koordinasi, yang di antaranya mensyaratkan sebelum berlatih atlet harus mempunyai kekuatan dan kecepatan yang baik; (2) apabila tidak mempunyai pondasi kekuatan dan kecepatan yang baik, resiko cedera akan tinggi pada tungkai atlet; (3) pelatih harus jeli dan pas dalam memberikan pemrograman metode latihan agility hurdle drill, karena apabila dosis latihan terlalu rendah batas ambang rangsang tidak tercapai dan apabila dosis latihan terlalu tinggi akan terjadi over training. Gerakan-gerakan latihan pada metode latihan agility hurdle drill sangat bermanfaat pada olahraga cabang bola voli. Gerakan-gerakan yang dilatih disesuaikan dengan teknik yang ada dalam bola voli dengan menggabungkan latihan untuk meningkatkan power dan koordinasi.

Agility ring drill didefinisikan sebagai

"Agility Ring are a portable footwork training tool designed to enhance power, quickness and agility" (www.power-system.com). Penjelasan selanjutnya mengemukakan bahwa agility ring drill adalah sebuah latihan gerak kaki menggunakan rintangan lingkaran yang dirancang untuk meningkatkan power tungkai dan koordinasi. Metode latihan agility ring drill ini dirancang untuk bagaimana atlet dapat bergerak secara cepat dan mengubah arah serta melewati lingkaran-lingkaran sebagai rintangan yang divariasikan. Agility ring drill dapat dipraktekkan pada area datar dan bebas dari penghalang. Agility ring drill dapat digunakan sebagai pemanasan maupun sebagai latihan inti dalam suatu periodisasi latihan. Metode latihan agility ring drill dapat dikembangkan dan diterapkan pada atlet-atlet junior terutama untuk pengembangan power tungkai dan koordinasi. Rintangan dibuat untuk pengembangan variasi latihan menghindar, mengubah arah tubuh, power tungkai dan pengkoordinasian gerakan-gerakan yang diperlukan dalam berbagai cabang olahraga. power tungkai dan koordinasi merupakan sebuah keterampilan yang dapat ditingkatkan melalui pengulangan latihan. Bentuk-bentuk latihan agility ring drill antara lain the tire run drill, the honeycomb drill, hopscotch drill.

Kelebihan metode latihan agility ring drill di antaranya; (1) pelatih dapat mengkreasikan bentuk latihan yang bermacam-macam dan kreatif sehingga atlet berantusias dalam menjalani sesi latihan; (2) bentuk latihan yang menyerupai permainan tradisional sehingga atlet lebih familiar dengan metode latihan agility ring drill; (3) metode latihan agility ring drill dapat dijadikan sebagai ajang kompetisi sehingga atlet akan bersemangat dan sekaligus melatih mental bertanding atlet; (4) metode latihan agility ring drill dapat diberikan pada pemanasan maupun inti latihan.

Kelemahan metode latihan agility ring drill di antaranya; (1) atlet harus mempunyai koordinasi kaki yang baik dalam melakukan adaptasi menggunakan metode latihan agility ring drill; (2) masih jarangnya peralatan alat yang diperjualbelikan sehingga harus memodifikasi alat latihan; (3) perlunya kreatifitas pelatih dalam mengembangkan metode latihan supaya tidak terjadi kebosanan atlet dalam melakukan latihan.

Gerakan-gerakan latihan pada metode latihan agility ring drill sangat bermanfaat pada olahraga cabang bola voli. Gerakan-gerakan yang dilatih disesuaikan dengan teknik yang ada dalam bola voli dengan menggabungkan 
latihan untuk meningkatkan power tungkai dan koordinasi.

Metode latihan agility hurdle drill dan metode latihan agility ring drill adalah dua metode latihan berbeda untuk mengembangkan biomotor terutama power tungkai dan koordinasi. Metode latihan agility hurdle drill dan metode latihan agility ring drill dikembangkan secara kreatif, variatif dan inovatif seperti permainan yang menantang. Hal ini merupakan bentuk metode latihan baru dengan asumsi bahwa banyak atlet junior yang belum pernah mengenal metode latihan ini, sehingga pada saat latihan ini di aplikasikan maka akan disukai dan dilakukan dengan sungguh-sungguh. Metode latihan agility hurdle drill dan metode latihan agility ring drill juga sebagai alternatif rekomendasi kepada pelatih-pelatih olahraga memberikan latihan komponen kebugaran biomotor power tungkai dan koordinasi yang disesuaikan dengan kondisi-kondisi latihan.

Metode latihan agility hurdle drill dengan metode agility ring drill adalah variabelvariabel dalam proses latihan yang mempengaruhi terhadap power tungkai dan koordinasi atlet bola voli junior putri. Atlet bola voli junior putri yang dilatih dengan metode latihan agility hurdle drill diduga akan memberikan pengaruh yang lebih tinggi daripada metode latihan agility ring drill terhadap peningkatan koordinasi atlet bola voli junior putri. Karena melalui metode latihan agility hurdle drill menggunakan rintangan-rintangan yang divariasikan dan menjadi metode latihan baru bagi atlet; pemrograman metode latihan agility hurdle drill yang baik akan menjadikan tingkat performa atlet menjadi optimal. Metode latihan agility hurdle drill mensyaratkan atlet harus mempunyai pondasi kekuatan dan kecepatan, sehingga atlet dalam melakukan latihan akan penasaran dan tertantang di dalam menyelesaikan sesi latihannya.

Atlet yang mempunyai keterampilan koordinasi tinggi dan atlet yang mempunyai keterampilan koordinasi rendah akan mempunyai perbedaan hasil dan memberikan pengaruh yang berbeda pula terhadap peningkatan power tungkai atlet bola voli junior putri. Dengan demikian diduga atlet yang mempunyai keterampilan koordinasi tinggi akan memberikan pengaruh lebih tinggi daripada atlet yang mempunyai keterampilan koordinasi rendah.

Atlet yang mempunyai koordinasi tinggi akan dapat melaksanakan gerakan secara efektif dan efisien dalam penggunaan waktu, ruangan dan energi, dalam melaksanakan suatu gerakan. Atlet yang mempunyai koordinasi tinggi akan dapat mengkoordinasikan beberapa gerak agar menjadi satu gerak yang utuh dan serasi, efisien dan efektif dalam penggunaan tenaga, untuk menghindari cedera, mempercepat berlatih, menguasai teknik, dapat untuk memperkaya taktik dalam bertanding, kesiapan mental atlet sehingga metode latihan yang sesuai adalah metode latihan agility hurdle drill. Sebaliknya atlet yang mempunyai koordinasi rendah akan kesulitan untuk dapat melaksanakan gerakan secara efektif dan efisien dan kemampuan untuk menyelesaikan tugas motorik secara cepat dan terarah yang ditentukan oleh proses pengendalian dan pengaturan gerakan serta kerjasama sistem persyarafan pusat akan lebih rendah dan lamban sehingga metode latihan yang sesuai adalah metode latihan agility ring drill. Metode latihan agility hurdle drill berbeda dengan metode latihan agility ring drill, demikian pula koordinasi tinggi berbeda dengan koordinasi rendah. Perbedaan tersebut akan mempunyai perbedaan hasil dan memberikan pengaruh yang berbeda pula terhadap peningkatan keterampilan koordinasi atlet bola voli junior putri.

Dengan demikian pelatih harus mampu untuk mengembangkan potensi atlet dan memberikan program latihan yang bermanfaat. Pelatih yang berperan dan berpengaruh dalam proses latihan, dituntut untuk memiliki berbagai kemampuan dalam usaha meningkatkan mutu latihan. Kualitas pelatih merupakan salah satu penentu di dalam pencapaian tujuan latihan.

\section{Metode}

Penelitian ini menggunakan pendekatan kuantitatif, adapun jenis penelitian yang digunakan dalam penelitian ini adalah menggunakan metode eksperimen (experiment). Menurut Arikunto (2010, p.9) menyatakan bahwa penelitian eksperimen merupakan suatu cara untuk mencari hubungan sebab akibat (hubungan kausal) antara dua faktor yang sengaja ditimbulkan oleh peneliti dengan mengeliminasi atau mengurangi atau menyisihkan faktor-faktor lain yang mengganggu.

Desain yang digunakan dalam penelitian ini adalah menggunakan metode eksperimen dengan desain faktorial $2 \times 2$. Digunakannya desain faktorial $2 \times 2$, karena metode eksperimen dalam penelitian ini melibatkan dua variabel independen (metode latihan agility hurdle drills dan metode latihan agility ring drills) yang masing-masing terdiri dari dua taraf 
dan kemampuan koordinasi atlet putri junior klub bola voli (tinggi dan rendah). Penentuan desain penelitian desain faktorial 2 x 2 merujuk pada Kerlinger (1990, pp.390-420). Rancangan penelitian dapat selengkapnya dapat dilihat pada tabel di bawah ini:

Tabel 1. Rancangan

Penelitian Desain Faktorial 2 x 2

\begin{tabular}{ccc}
$\begin{array}{c}\text { MetodeLatihan } \\
\text { (A) }\end{array}$ & $\begin{array}{c}\text { Metode } \\
\text { Latihan } \\
\text { Agility Hurdle } \\
\text { Drill (A1) }\end{array}$ & $\begin{array}{c}\text { Metode } \\
\text { Latihan } \\
\text { Agility Ring } \\
\text { Drill (A2) }\end{array}$ \\
\cline { 1 - 2 } $\begin{array}{c}\text { Koordinasi } \\
\text { (B) }\end{array}$ & A1B1 & A2B1 \\
\cline { 1 - 1 } Tinggi (B1) & A2B1 & A2B2 \\
Rendah (B2) & & \\
\hline
\end{tabular}

Keterangan:

Hasil power tungkai yang memiliki

A1B1 : koordinasi tinggi dilatih dengan metode latihan agility hurdle drill. Hasil power tungkai yang memiliki

A1B2 : koordinasi rendah dilatih dengan metode latihan agility hurdle drill. Hasil power tungkai yang memiliki

A2B1 : koordinasi tinggi dilatih dengan metode latihan agility ring drill. Hasil power tungkai yang memiliki

A2B1 : koordinasi rendah dilatih dengan metode latihan agility ring drill.

Hasil eksperimen yang menggunakan desain faktorial akan memperoleh informasi tentang kontribusi masing-masing variabel independen terhadap hasil perlakuan dan interaksi di antara variabel-variabel yang dilibatkan. Kelebihan menggunakan penelitian eksperimen desain faktorial adalah kemampuan untuk memperoleh informasi mengenai interaksi di antara variabel-variabel independen yang mempengaruhi variabel dependen.

Waktu dan Tempat Penelitian

Tempat pelaksanaan penelitian berada di klub Bola Voli Spirit di GOR KONI Sleman dan klub Bola Voli Pervas di GOR AAU, Kabupaten Sleman, Daerah Istimewa Yogyakarta. Pelaksanaan penelitian dilaksanakan selama dua bulan dimulai pada tanggal 18 November 2012 sampai dengan tanggal 28 Desember 2012.

Populasi Penelitian dan Sampel Penelitian

Menurut Sugiyono (2007, p.80) populasi adalah wilayah generalisasi yang terdiri atas; objek/subjek yang mempunyai kuantitas dan karakteristik tertentu yang diterapkan oleh peneliti untuk dipelajari dan ditarik kesimpulannya. Populasi pada penelitian ini adalah seluruh atlet putri junior klub Bola Voli Spirit dan klub Bola Voli Pervas. Pengambilan sampel ini dilakukan sedemikian rupa sehingga diperoleh sampel yang benar-benar dapat mewakili dan dapat menggambarkan keadaan populasi yang sebenarnya. Menurut Suharyadi, dkk (2011, p.7) sampel adalah suatu bagian dari populasi tertentu yang menjadi perhatian atlet yang menjadi sampel penelitian masuk ke dalam golongan atlet putri junior klub Bola Voli Spirit dan klub Bola Voli Pervas. Atlet yang menjadi sampel secara fisiologis mempunyai karakteristik yang relatif sama.

Untuk menentukan sampel pada penelitian ini dilakukan langkah-langkah sebagai berikut: (1) Secara Purposive sampel ditentukan yaitu seluruh atlet putri junior klub Bola Voli Spirit dan klub Bola Voli Pervas; (2) Kriteria sampel yaitu jenis kelamin perempuan, tidak ada kelainan fisik atau sakit; (3) Selanjutnya terhadap ke 44 orang siswa tersebut dilakukan tes pendahuluan menggunakan Hexagonal Obstacle Test, yaitu untuk memperoleh tingkat koordinasi masing-masing atlet; (4) Dari hasil tes pendahuluan tersebut disusun ranking; (5) Untuk menentukan sampel tingkat koordinasi yang tinggi dan rendah digunakan persentase, yang mengacu pada Arikunto (2012, p.227) yakni untuk menentukan sampel dalam kelompok besar yaitu dengan mengambil dua kutubnya saja, yakni $27 \%$ skor teratas sebagai kelompok tinggi dan $27 \%$ skor terbawah sebagai kelompok rendah. Dengan demikian dalam setiap kelompok metode latihan terdapat 20 orang atlet $(27 \%$ x $44=11,8$ dibulatkan jadi 12$)$ yang tingkat koordinasi tinggi dan rendah, sehingga diperoleh empat kelompok yang masing-masing terdiri dari 6 orang, yaitu dua kelompok (tinggi dan rendah) untuk metode latihan agility hurdle drills dan dua kelompok (tinggi dan rendah) untuk metode latihan agility rings drills. Sisa calon sampel yang memperoleh skor di antara kelompok atas dan bawah (24 orang) tidak diikut sertakan dalam penelitian; 6) Akhirnya diperoleh jumlah sampel penelitian secara keseluruhan yaitu 24 orang. Agar lebih jelas, komposisi pengelompokan sampel eksperimen dapat dilihat dalam tabel di bawah ini: 
Tabel 2. Komposisi

Pengelompokan Sampel Eksperimen.

\begin{tabular}{ccc}
\hline $\begin{array}{c}\text { Metode Latihan } \\
\text { (A) }\end{array}$ & $\begin{array}{c}\text { Metode } \\
\text { Latihan } \\
\text { Agility Hurdle } \\
\text { Drill (A1) }\end{array}$ & $\begin{array}{c}\text { Metode } \\
\text { Latihan } \\
\text { Agility Ring } \\
\text { Drill (A2) }\end{array}$ \\
$\begin{array}{c}\text { Koordinasi } \\
\text { (B) }\end{array}$ & 6 & 6 \\
\hline Tinggi (B1) & 6 & 6 \\
Rendah (B2) & 6 & \\
\hline
\end{tabular}

Variabel Penelitian

Menurut Hatch dan Farhady (Sugiyono, 2007, p.38) variabel dapat didefinisikan sebagai atribut dari seseorang atau objek yang mempunyai variasi antara satu orang dengan yang lain atau satu objek dengan objek yang lain. Menurut Arikunto (2010, p.161) variabel adalah objek penelitian, atau apa yang menjadi titik perhatian suatu penelitian.

Penelitian ini melibatkan dua variabel bebas yang dimanipulasi, satu variabel bebas yang dikendalikan (atribut), satu variabel terikat dan satu variabel moderator. Variabel bebas yang dimanipulasi terdiri atas; (1) metode latihan agility hurdle drills dan (2) metode latihan agility rings drills. Metode latihan agility hurdle drill merupakan bentuk latihan untuk mengubah arah dan posisi tubuh secara eksplosif dengan cepat dan tepat melewati rintangan-rintangan dengan koordinasi-koordinasi gerakan. Metode latihan agility ring drill merupakan bentuk latihan power dan koordinasi yang digunakan untuk mengubah arah dan posisi tubuh secara eksplosif, cepat dengan menggunakan kordinasi-koordinasi serta keseimbangan tubuh untuk melewati rintangan-rintangan berbentuk lingkaran.

Variabel bebas yang dikendalikan (atribut) adalah koordinasi, yang terdiri atas (1) koordinasi tungkai tinggi dan (2) koordinasi tungkai rendah. Koordinasi adalah kemampuan seseorang untuk merangkaikan beberapa unsur gerak menjadi satu gerakan yang selaras sesuai dengan tujuannya. Variabel terikat adalah power tungkai atlet putri junior klub bola voli. power adalah kemampuan otot atau sekelompok otot seseorang untuk mempergunakan kekuatan maksimal yang dikerahkan dalam waktu yang sependek-pendeknya.

Teknik Instrumen Pengumpulan Data

Prinsip suatu penelitian adalah melakukan pengukuran dan harus ada alat ukur yang baik. Alat ukur dalam penelitian biasa dinamakan dengan instrumen penelitian seperti yang dikemukakan oleh Sugiyono (2007, p.102) instrumen penelitian adalah suatu alat yang digunakan untuk mengukur fenomena alam maupun sosial yang diamati, secara spesifik semua fenomena itu disebut variabel penelitian. Instrumen penelitian secara garis besar bisa digolongkan menjadi dua, yaitu yang berbentuk tes dan non tes, sesuai dengan penelitian ini peneliti menggunakan penelitian berupa tes. Mengenai tes Arikunto (2010, p.193) mengemukakan bahwa tes adalah serentetan pertanyaan atau latihan serta alat lain yang digunakan untuk mengukur keterampilan, pengetahuan inteligensi, kemampuan atau bakat yang dimiliki oleh individu atau kelompok. Adapun instrumen penelitian yang digunakan dalam penelitian ini adalah tes koordinasi menggunakan Hexagonal Obstacle Test. Menurut Customs (2012, p.14) agility and coordination are essential to any officer trained to apply use of force. This test measures the ability, balance and coordination. Tes hexagonal merupakan sebuah tes untuk mengukur kelincahan dan koordinasi kaki. Dalam melakukan tes hexagonal memerlukan sebuah alat tes berbentuk segi enam dan dalam melakukan tes dengan meloncat bolak balik melewati sisi segi enam. Tes power tungkai meng-gunakan Sargen Jump Test/Vertical Jump Test. Menurut Evans (2006, p.1) The vertical jump can play a significant role for many athletes in various competitive sports. Teknik pengumpulan data pada penelitian ini menggunakan tes untuk mengukur suatu keterampilan kemampuan power tungkai dan koordinasi. Data yang dikumpulkan dalam penelitian ini yaitu berupa data dari hasil tes menggunakan Hexagonal Obstacle Test dan Sargent Jump Test atau Vertical Jump Test sebelum dan sesudah perlakuan (treatment).

Validitas Instrumen dan Reliabilitas Instrumen

Suatu alat ukur dinyatakan valid, apabila alat ukur tersebut betul-betul mengukur apa yang hendak diukur. Menurut Arikunto (2010, p.211) validitas adalah suatu ukuran yang menunjukkan tingkat-tingkat kevalidan atau kesahihan sesuatu instrumen. Suatu instrumen dikatakan valid apabila instrumen tersebut mampu mengukur apa yang hendak diukur. Tes memiliki validitas yang tinggi jika hasilnya sesuai dengan kriteria, dalam arti memiliki kesejajaran antara tes dan kriteria. Jadi validitas alat ukur akan mungkin terjadi apabila alat ukur itu tetap mengukur variabel-variabel yang diteliti.

Menurut Mackenizie (2005, p.58) validity of hexagonal obstacle test there are 
publised tables to relate results to potential level of fitness and the correlation is high. Jadi uji validitas mengacu pada sejauh mana menguji benar-benar mengukur apa klaim untuk mengukur dan sejauh mana kesimpulan dan keputusan dibuat berdasarkan skor tes yang sesuai dan bermakna. Tes ini menyediakan sarana untuk memonitor efek dari pelatihan pada pembangunan fisik atlet. Menurut Ismaryati (2006, p.46) sasaran tes Hexagonal Obstacle untuk anak usia 10 tahun ke atas. Tes Hexagonal Obstacle memiliki tingkat validitas 0,912 (Widiyanto, 2012, p.73).

Validitas instrumen Sargent Jump Test atau Vertical Jump Test menurut Mackenzie (2005, p.129) validity of sargent jump test there are publised tables to relate results to potential level of fitness and the correlation is high. Jadi uji validitas mengacu pada sejauh mana menguji benar-benar mengukur apa klaim untuk mengukur dan sejauh mana kesimpulan dan keputusan dibuat berdasarkan skor tes yang sesuai dan bermakna. Taryono (http://ejournalunisma.net/ojs/index.php/motion/article/view/3 4) validitas instrumen Sar-gent Jump Test atau Vertical Jump Test sebesar 0,86.

Menurut Safrit dan Wood (1989,p.45) reliability is an important characteristic of a test, because it influences the validity of a test and because without reliability no faith can be put in scores from a test. Suatu alat ukur dikatakan reliabel (terandal), apabila alat ukur tersebut mempunyai derajat keajegan. Reliabilitas instrumen hexagonal obstacle test menurut Mackenzie $(2005$, p.58) reliability would depend upon how strict the test is conducted and the individual's level of motivation to perform the test. Jadi uji reliabilitas mengacu pada sejauh mana tes adalah konsisten dan stabil dalam mengukur apa yang dimaksudkan untuk mengukur. Keandalan akan tergantung pada seberapa ketat tes dilakukan dan tingkat individu motivasi untuk melakukan tes. Menurut Ismaryati (2006, p.46) sasaran tes Hexagonal Obstacle untuk anak usia 10 tahun ke atas. Tes Hexagonal Obstacle memiliki tingkat reliabilitas 0,950 (Widiyanto, 2012, p.73).

Reliabilitas instrumen Sargent Jump Test atau Vertical Jump Test menurut Mackenzie (2005, p.129), reliability would depend upon how strict the test is conducted and the individual's level of motivation to perform the test. Jadi uji reliabilitas mengacu pada sejauh mana tes adalah konsisten dan stabil dalam mengukur apa yang dimaksudkan untuk meng- ukur. Keandalan akan tergantung pada seberapa ketat tes dilakukan dan tingkat individu motivasi untuk melakukan tes. Taryono (http://ejournal-unisma.net/ojs/index.php/motion/article/view/34) validitas instrumen Sargent Jump Test atau Vertical Jump Test sebesar 0,92.

\section{Teknik Analisis Data}

Setelah data koordinasi atlet putri junior klub Bola Voli Spirit dan Klub Bola Voli Pervas terkumpul, langkah selanjutnya adalah mengolah dan menganalisis data tersebut. Pada bagian ini akan diuraikan mengenai teknik analisis data hasil tes, terhadap metode latihan agility hurdle drill dan agility ring drill. Teknik analisis data yang digunakan adalah teknik analisis varians (anava) dua jalur. Selanjutnya uji lanjutan menggunakan uji rentang NewmanKeuls. Untuk memenuhi asumsi dalam teknik anava, maka dilakukan uji normalitas menggunakan uji Kolmogorov Smirnov dan uji homogenitas varians menggunakan uji Levene test.

\section{Hasil Penelitian dan Pembahasan}

Dari hasil penelitian menunjukkan bahwa metode latihan agility hurdle drill dan metode latihan agility ring drill tidak mempunyai pengaruh yang signifikan terhadap peningkatan power tungkai atlet bola voli junior putri. Hal ini dibuktikan dengan nilai $0.741>0.05$. Dengan demikian berarti bahwa metode latihan agility hurdle drill dan metode latihan agility ring drill tidak mempunyai pengaruh yang signifikan terhadap peningkatan power tungkai atlet bola voli junior putri dapat diterima kebenarannya.

Dari hasil penelitian menunjukan bahwa metode latihan agility hurdle drill tidak mempunyai perbedaan yang signifikan dan mempunyai pengaruh yang sama terhadap power tungkai atlet bola voli junior putri. Hal ini dibuktikan dengan nilai $\mathrm{F}_{\text {hitung }}$ sebesar 0.045 $<\mathrm{F}_{\text {tabel }}$ sebesar 4.28 pada taraf signifikansi 5\% atau $0.835>0.05$. Dengan demikian hipotesis nol (Ho) diterima, yang berarti bahwa metode latihan agility hurdle drill memiliki peningkatan yang tidak berbeda dengan metode latihan agility ring drill dapat diterima kebenarannya.

Dari hasil penelitian menunjukan bahwa atlet bola voli junior putri yang memiliki tingkat koordinasi tinggi memiliki peningkatan koordinasi yang berbeda dengan atlet bola voli junior putri yang memiliki tingkat koordinasi rendah. Hal ini dibuktikan dari nilai $F_{\text {hitung }}$ sebesar $136.22>\mathrm{F}_{\text {tabel }}$ sebesar 4.28 pada taraf 
signifikansi $5 \%$ atau $0.000<0.05$. Dengan demikian hipotesis nol (Ho) ditolak, yang berarti bahwa atlet bola voli junior putri yang memiliki tingkat koordinasi tinggi memiliki peningkatan yang berbeda dengan atlet bola voli junior putri yang memiliki tingkat koordinasi rendah dapat diterima kebenarannya. Dari hasil analisis diperoleh bahwa atlet bola voli junior putri yang memiliki tingkat koordinasi tinggi ternyata memiliki peningkatan koordinasi lebih baik daripada atlet bola voli junior putri yang memiliki tingkat koordinasi rendah dengan rata-rata peningkatan masing-masing yaitu atlet bola voli junior putri yang memiliki tingkat koordinasi tinggi sebesar 10.7417 dan atlet bola voli junior putri yang memiliki tingkat koordinasi rendah sebesar 16.0342.

Dari hasil penelitian menunjukan bahwa tidak menunjukan interaksi antara metode latihan dan koordinasi terhadap power tungkai yang bermakna. Hal ini dibuktikan dengan $\mathrm{F}_{\text {hitung }}$ sebesar $1.890<\mathrm{F}_{\text {tabel }} 4.28$, pada taraf signifikansi $5 \%$ atau $0.184>0.05$. Dengan demikian hipotesis nol (Ho) diterima, jadi dapat disimpulkan bahwa tidak terdapat interaksi yang signifikan antara metode latihan dengan koordinasi atlet bola voli junior putri.

Berdasarkan pengujian-pengujian telah dihasilkan pembahasan sebagai berikut:

Perbedaan Peningkatan Power Tungkai Atlet Bola Voli Junior Putri melalui Metode Latihan Agility Hurdle Drills dan Metode Latihan Agility Ring Drills.

Berdasarkan hasil analisis data penelitian dinyatakan bahwa hipotesis penelitian tentang terdapat peningkatan power tungkai atlet bola voli junior putri melalui metode latihan agility hurdle drills dan metode latihan agility ring drills ditolak, hal ini berarti bahwa kedua metode latihan tersebut tidak memiliki pengaruh terhadap peningkatan power tungkai bola voli junior putri.

Berdasarkan kajian teori di depan dijelaskan bahwa kondisi fisik dalam olahraga prestasi merupakan komponen yang sangat penting yang akan mendukung dalam pencapaian prestasi yang optimal, oleh karena itu dalam peningkatan dan pemeliharaan unsur kondisi fisik merupakan aspek penting yang harus dilakukan secara berkesinambungan. Power merupakan salah satu komponen fisik yang harus dimiliki oleh para atlet di mana atlet harus bisa mengerahkan kekuatan secara eksplosif dalam waktu yang sesingkat-singkatnya. Urutan latihan un- tuk meningkatkan power diberikan setelah olahragawan dilatih unsur kekuatan dan kecepatan. Power sangat dipengaruhi oleh dua unsur komponen fisik lainnya yaitu kekuatan otot dan kecepatan. Kedua komponen fisik ini tidak dapat dipisahkan, karena pada prinsip kerjanya kedua koponen fisik ini bekerja bersama-sama untuk menghasilkan kemampuan daya ledak otot (power). Dasar dari pembentukan power adalah kecepatan dan kekuatan, maka sebelum melatih kondisi fisik power maka kondisi fisik kekuatan dan kecepatan harus dilatihkan terlebih dahulu. Sebelum latihan kondisi fisik power seorang atlet harus memiliki tingkatan kekuatan dan kecepatan yang baik. Tidak terdapat peningkatan power tungkai atlet bola voli junior putri melalui metode latihan agility hurdle drills dan metode latihan agility ring drills secara nyata, dikarenakan oleh banyak faktorfaktor yang mempengaruhi. Diantaranya adalah faktor-faktor kondisi fisik kekuatan dan kecepatan atlet yang belum baik sehingga metode latihan agility hurdle drills dan metode latihan agility ring drills yang diberikan tidak berpengaruh secara maksimal pada power tungkai atlet bola voli junior putri.

Perbedaan Pengaruh Metode Latihan Agility Hurdle Drill dan Metode Latihan Agility Ring Drill terhadap Peningkatan Power Tungkai Atlet Bola Voli Junior Putri.

Berdasarkan hasil analisis data penelitian dinyatakan bahwa hipotesis penelitian tentang adanya perbedaan pengaruh antara metode latihan agility hurdle drill dan metode latihan agility ring drill terhadap peningkatan koordinasi atlet bola voli junior putri diterima hal ini berarti bahwa kedua metode latihan tersebut memiliki pengaruh yang sama terhadap peningkatan koordinasi atlet bola voli junior putri.

Berdasarkan kajian teori di depan dijelaskan bahwa metode latihan agility hurdle drill dan metode latihan agility ring drill mempunyai kelebihan dan karakteristik masing-masing di dalam meningkatkan koordinasi atlet bola voli junior putri. Pada metode latihan agility hurdle drill mempunyai kelebihan menggunakan rintangan-rintangan yang divariasikan dan menjadi metode latihan baru bagi atlet, sehingga atlet dalam melakukan latihan akan penasaran dan tertantang di dalam menyelesaikan sesi latihannya. Di dalam latihan agility hurdle drill memungkinkan atlet selain untuk melatih koordinasi juga untuk melatih power loncatan atlet yang digunakan dalam melakukan smash, 
block, dan servis. Pada metode latihan agility ring drill mempunyai kelebihan yaitu bentuk latihan ini dapat dikreasikan dengan bentuk latihan yang menantang sehingga atlet berantusias dalam menjalani sesi latihan. Metode latihan agility ring drill juga dapat dijadikan sebagai ajang kompetisi yang dapat diberikan pada awal maupun inti latihan. Hasil penelitian membuktikan bahwa metode latihan agility hurdle drill dan metode latihan agility ring drill memberikan pengaruh yang sama terhadap koordinasi atlet bola voli junior putri.

Perbedaan Atlet Bola Voli Junior Putri yang Mempunyai Koordinasi Tinggi dan Koordinasi Rendah.

Berdasarkan pengujian hipotesis ke dua ternyata terdapat perbedaan pengaruh yang signifikan antara kelompok atlet yang mempunyai koordinasi tinggi dan koordinasi rendah terhadap peningkatan koordinasi atlet bola voli junior putri. Pada kelompok atlet yang mempunyai koordinasi tinggi mempunyai peningkatan koordinasi yang lebih baik dibandingkan dengan kelompok atlet yang mempunyai koordinasi rendah.

Koordinasi adalah kemampuan seseorang untuk merangkaikan beberapa unsur gerak menjadi satu gerakan yang selaras sesuai dengan tujuannya. Koordinasi merupakan kemampuan untuk menyelesaikan tugas motorik secara cepat dan terarah yang ditentukan oleh proses pengendalian dan pengaturan gerakan serta kerja sama sistem persyarafan pusat. Fungsi koordinasi dalam bola voli adalah dapat melaksanakan gerakan secara efektif dan efisien. Efektif dalam kaitan ini berhubungan dengan efisiensi penggunaan waktu, ruangan dan energi, dalam melaksanakan suatu gerakan. Sedangkan efektif berkaitan dengan efektivitas proses yang dilalui dalam mencapai tujuan, mengkoordinasikan beberapa gerak agar menjadi satu gerak yang utuh dan serasi, efisien dan efektif dalam penggunaan tenaga, untuk menghindari cedera, mempercepat berlatih, menguasai teknik, dapat untuk memperkaya taktik dalam bertanding, kesiapan mental atlet lebih mantap untuk menghadapi pertandingan. Atlet yang mempunyai koordinasi yang tinggi lebih diuntungkan karena memiliki kemampuan untuk beradaptasi terhadap pelaksanaan gerakan yang efektif dan efisien. Dari angka-angka yang dihasilkan dalam analisis data menunjukan bahwa perbandingan rata-rata peningkatan kelompok atlet yang mempunyai koordinasi tinggi sebesar 5.2925, lebih tinggi dari pada kelompok atlet yang mempunyai koordinasi rendah.

Pengaruh Interaksi antara Metode Latihan dan Koordinasi Terhadap Power Tungkai Atlet Bola Voli Junior Putri.

Berdasarkan analisis varians, hipotesis penelitian tentang adanya interasi antara metode latihan (agility hurdle drill dan agility ring drill) dengan koordinasi (tinggi dan rendah) dinyatakan tidak terdapat interaksi yang signifikan antara keduanya. Hal ini berarti $\mathrm{H}_{0}$ diterima dan $\mathrm{H}_{1}$ ditolak antara metode latihan dan koordinasi tidak memiliki pengaruh terhadap koordinasi atlet bola voli junior putri.

\section{Daftar Pustaka}

Anonim. (2012). What are mini \& micro hurdle. (Online). Tersedia: http://www.alphadogsports.com/pdf/Hurdles\%20Man ual.pdf. Diunduh tanggal 1 Agustus 2012.

Arikunto, Suharsimi. (2010). Prosedur penelitian, suatu pendekatan praktek. Jakarta: PT. Rineka Cipta.

(2012). Dasar-dasar evaluasi pendidikan. Jakarta: PT. Bumi Aksara.

Bompa, Tudor O. (1999). Periodization: theory and methodology of training, $\left(4^{\text {th }}\right.$ edition). Dubuque, Lowa: Kendal/Hunt Publising Company.

Customs. (2012). Australian customs service basic functional fitness assessment protocol. (Online). Tersedia: http://customs.gov.au/webdata/resources/files/C T_FitnessProtocol.pdf. Diunduh tanggal 1 Oktober 2012.

Evans, Tom. (2006). The effects of static stretching on vertical jump performance. USA: Marshal University.

Ghosh, Arabinda. (2005). Manual of training for government officials. Administrative Training Institute. Government of West Bengal: Bidhan Nagar, Kol-kata. Jurnal. Tersedia: Error! Hyperlink reference not valid. Diunduh tanggal 18 Juli 2012. 
Ismaryati. (2006). Tes pengukuran olahraga. Surakarta: Lembaga Pengembangan Pendidikan (LPP) dan UPT Penerbitan dan Percetakan UNS (UNS Press). Universitas Sebelas Maret Surakarta.

Kerlinger, Fred N. 1990. Asas-asas penelitian behavioral, Edisi terjemahan. Yogyakarta: Gadjah Mada University Press.

Komi, Paavo V. (2003). Strength and power in sport. Great Britain: MPG Books Ltd, Bodmin, Cornwall.

Mackenzie, Brian. (2005). 101 Performance evaluation tests. London: The Flying Fish Studios Ltd. Electric Word plc.

Simmons, Louie. (2012). Explosive power and strength. (Online). Tersedia: www.westside-barbell.com. Diunduh tanggal 1 Agustus 2012.

Sugiyono, (2007). Metode penelitian kuantitatif kualitatif dan $R \& D$. Bandung. Alfabeta.

Sukadiyanto. (2010). Pengantar teori dan metodologi melatih fisik. Yogyakarta: FIK UNY.
Taryono. (2012). Kontribusi kekuatan otot tungkai dan otot lengan terhadap hasil pukulan spike dalam permainan bolavoli. (Online). Tersedia: http://www.google.com/url?sa=t\&rct=j $\& \mathrm{q}=$ Kontribusi $\% 20$ kekuatan $\% 20$ otot $\%$ 20tungkai\%20dan\%20otot\%20lengan\% 20terhadap $\% 20$ hasil $\% 20$ pukulan $\% 20$ sp ike\%20dalam\%20permainan\%20bola voli\&source $=$ web $\& c d=1 \& c a d=r j a \& v e d$ $=0 \mathrm{CC} 0 \mathrm{QFjAA} \& u r \mathrm{l}=\mathrm{http}: / / \mathrm{www}$. ejourn al-unisma.net/ojs/index.php/motion/article/download/34/32\&ei= $746 \mathrm{Uc}$ WJEczprQejrIHIDw\&usg=AFQjCNFE sCPKPHvxVMfApHwkzAd_zyRc6Q\& sig2=UP_1YxdByeD1LuepMiIg0Q\&bv $\mathrm{m}=$ bv.43287494,d.bmk. Diunduh tanggal 18 Juli 2012.

Widiyanto, Tri. (2012). Hubungan antara kelincahan dan kelentukan terhadap keterampilan sepak sila siswa SD Negeri 2 Bojanegara Kecamatan Padamara Kabupaten Purbalingga yang mengikuti ekstrakurikuler sepak takraw. Skripsi. FIK: Universitas Negeri Yogyakarta. 